\title{
Inhalt
}

Carina Kühne-Wespi, Klaus Oschema, Joachim Friedrich Quack

Zerstörung von Geschriebenem

Für eine Phänomenologie des Beschädigens und Vernichtens -1

\section{Damnatio memoriae}

Joachim Friedrich Quack

„Lösche seinen Namen aus!“

Zur Vernichtung von personenreferenzierter Schrift und Bild im Alten Ägypten — 43

Ulrike Ehmig

Rasuren in lateinischen Inschriften

Beobachtungen zu ihrer Verbreitung und ihrem nicht-öffentlichen Gebrauch — 103

\section{(,Massenhafte“) Zerstörung von Büchern}

Georges Declercq

The Medium and the Message

The Public Destruction of Books and Documents in the European Middle Ages — 123

Marco Mostert

Between Carelessness and Wilful Destruction

The Demise of Texts and Their Manuscripts in the Medieval West —149

Christophe Vuilleumier

From Censorship to Taboos in the $19^{\text {th }}$ and $20^{\text {th }}$ Centuries -167

Enno Giele

Von Autodafé bis Rasur

Aspekte der Zerstörung von Geschriebenem und das Beispiel China — 179

\section{Zerstörung von Geschriebenem im administrativen Kontext}

Jannik Korte

Zerreißen, Durchstreichen, Auswischen

Zerstörung von demotischen (und einer abnormhieratischen) Rechtsurkunden -229 
Konrad Knauber

Zerschlagene Siegel im mittelalterlichen Totenkult - vom „Altmetall“ zum Symbolakt -261

\section{Magisch-rituelle Auslöschung}

Adrian C. Heinrich

Durchlöchert, verbrannt, begraben

Zur Zerstörung beschrifteter Figurinen in therapeutischen Ritualen aus

Mesopotamien (1. Jahrtausend v. Chr.) -287

Annette Hornbacher

Schriftverbrennung als kosmologische Realisierung

Eine balinesische Perspektive auf die Handlungsmacht von Schrift -315

\section{Einverleibung von Schrift}

Carina Kühne-Wespi

Papyrus trinken und Hieroglyphen essen

Praktiken der Schriftverinnerlichung im pharaonischen Ägypten — 341

Katherine Storm Hindley

Eating Words and Burning Them

The Power of Destruction in Medieval English Charm Texts — 359

Katharina Wilkens

Text als Medizin

Ablöschen und Trinken koranischer Verse als therapeutische Praxis _ 373

\section{Zerstörung von Geschriebenem als literarisches Motiv}

\section{Gereon Becht-Jördens}

Die verlorene Handschrift

Zum Motiv von Zerstörung, Verlust und Wiederauffindung als Strategie der Traditionssicherung in der lateinischen Literatur des Mittelalters — 393

Vorstellung der Autorinnen und Autoren -437

Index -441 